DOI: 10.15587/2312-8372.2017.105351

\title{
Vdovychenko v. DEVELOPMENT OF A MODEL FOR DETERMINING THE TIME PARAMETERS FOR THE INTERACTION OF PASSENGER TRANSPORT IN A SUBURBAN TRANSPORT AND TRANSFER TERMINAL
}

Сформована загальна структура та формалізовані складові елементи моделі технологічної взаємодії пасажирського транспорту в приміському транспортно-пересадочному терміналі. На основі оцінки загального часу пересадки пасажирів виділені характеристичні умови та області допустимих значень ращіональної тривалості часу суміжного знаходження транспортних засобів у приміському транспортно-пересадочному терміналі.

Ключові слова: приміський транспортно-пересадочний термінал, пасажирський транспорт, час пересадки пасажирів, час суміжного простою.

\section{Introduction}

The technological process of passenger transportation is a sequence of interrelated operations, the implementation of which should ensure the movement of passengers from the point of departure to the destination. The organization of the technological process largely determines the quality of transport services and has a significant impact on the level of their economic and social efficiency. When developing the technology of passenger transportation, it is necessary to take into account a number of features and requirements, which include:

- a clear planning of the work of all participants in the transport process;

- the need to ensure the uninterrupted transport process; - ensuring the safety of participants in the transport process;

- a clear interaction of participants in the technological process.

An important element of the organization of the technological process of servicing the suburban population is the functioning of suburban transport and transfer terminals (TTT). Suburban TTT is the main constructive element of the transport spatial planning organization of the city and adjacent territories. The network of suburban TTT represents the centers of the branching of the city's transport highways, thanks to its growth, the connections between the territorial structures of cities and suburban areas, satellite towns and agglomerations are expanding. The place of TTT in the transport infrastructure determines its transport work, that is, the organization of interaction between internal and suburban communications, city and intercity communication. In the hierarchical structure of the elements, the value of TTT is determined by the scales of the zones of their influence and, accordingly, the availability of the node, its transport and functional structure. Suburban TTTs in the transport network concentrate information about the number, capacity, distribution of passenger traffic between the routes, service and the network. Modern suburban TTTs are complex entities, which put forward specific requirements for the organization of technological interaction of routes within their functional and organizational structure. It shows the relevance of the study.

\section{The object of research and its technological audit}

The technological process of passenger transport service on the one hand can be presented as an integral element of the higher level process - the functioning of the transport system, and on the other hand it is considered as a set of elementary technological operations. The composition of technological operations performed at transport infrastructure facilities, which include suburban TTT includes: provision of a vehicle for boarding passengers, loading and unloading of the passengers, selling tickets, maneuvering vehicles, time between trips. On the basis of technological audit of operating TTT, it is revealed that the most important parameters are the following:

- number of types and routes of the transport interacting in the node;

- number of resource channels of service;

- technological service performance.

The parameters of the TTT elements are:

- capacity of resource channels;

- capacity of its resource economy.

The parameters of the flows entering and exiting the TTT are:

- their absolute value;

- time (daily, weekly, seasonal, etc.) and spatial unevenness;

- intensity of flows;

- the distribution function of the intervals between the arrival times of the two transport units;

- system of priorities for the receipt and dispatch of vehicles;

- regularity of the transport flow. 
The object of research is the process of suburban TTT functioning. An important characteristic of suburban TTT functioning is the time parameters of passenger service. Reducing the time of transfer of passengers between the types of services and routes makes it possible to improve the quality of transport services to the suburban population, and to increase the social efficiency of passenger transport. Reducing the time of transfer of passengers can be realized by ensuring the simultaneous presence in TTT vehicles of different routes. Under such conditions, the waiting time for transfer between routes will be minimal. However, the extension of the time of the adjacent location of vehicles in the TTT leads to an increase in their unproductive idle time, a reduction in their productivity and an increase in the probability of a malfunction in the TTT operation. Determination of rational time parameters for the interaction of routes requires the creation of an adequate model for TTT functioning and for the research of the parametric regions of its constituent elements. The study of the time parameters of the simultaneous location of vehicles in the TTT from the standpoint of providing service-resource efficiency has an insufficient level of study, has so far been presented only in general terms, does not have a specific formalization and requires the creation of a corresponding model apparatus.

\section{The aim and objectives of research}

The aim of research is determination of the interval of rational time parameters for the technological interaction of passenger transport in suburban TTT.

To achieve this aim, it is necessary to solve the following tasks:

1. To form the general structure of the interaction of subjects within the suburban TTT.

2. To formalize models for determining the boundaries of the permissible parametric regions of time interaction of passenger transport.

\section{Research of existing solutions of the problem}

In the conditions of continuous development of interrelations between the city and other settlements, the requirements to the transport infrastructure, the interaction of its elements in transport hubs are increasing [1]. The issues of organizing the interaction of passenger transport within the TTT are considered from the following forms:

- planning solutions [2-4];

- technical interaction [5];

- technological coordination [6-9].

The organization of interaction of passenger transport by searching for a rational planning structure of TTT has become widespread in scientific research. This form allows to determine rational parameters for the location of service channels at the design stage of the elements of the transport system and is aimed at creating conditions for the conflict-free movement of traffic and pedestrian flows within the TTT. This form allows to ensure the formation of a high level of the future potential of interaction of elements within the TTT, but can't be considered as an effective tool for improving the operational efficiency of the technological processes of passenger transport.
Technical cooperation implies the harmonization of the operational parameters of devices and vehicles and is aimed at reducing the likelihood of malfunctions in the TTT operation and ensuring the traffic safety. The limited application of this approach consists in the need to replace the technical equipment of the subjects of passenger transport that makes it impossible in conditions of limiting the resource capabilities of transport organizations. In addition, this form of organization of interaction without technological coordination does not allow achieving a high level of quality of passenger transport services.

The most promising method is the technological interaction, which involves the introduction of rational traffic schedules within the TTT. The existing methods of coordinating the movement of passenger transport in the organization of interaction within the framework of the TTT are implemented on the basis of:

- allowance for stochastic motion [10];

- the number of passenger transfers [11];

- taking into account the periods of possible transfer

of passengers [12];

- assessing transit flows [13];

- multi-criteria evaluation of the results [14].

A common disadvantage of the existing approaches to technological coordination of the interaction of transport in the TTT is that they do not take into account the potential possibilities to ensure a reduction in the time of passenger transfer by creating conditions for the simultaneous stay of vehicles in the TTT.

Taking into account the above-mentioned disadvantages of the existing approaches to the interaction of passenger transport in the TTT, it is necessary to conduct a study aimed at analyzing the time parameters of stay of vehicles in the TTT from the standpoint of reducing the waiting time for the passengers. Research in this area is considered promising also from the point of view of ensuring the conditions of service-resource compliance with the requirements of the stability of technological processes of transport entities.

\section{Methods or research}

The process of TTT functioning can be represented in the form of a model consisting of the structure of its constituent elements and the contour of their interrelations. The components of the TTT are: bus stops $\left(S S_{i}\right)$, metro station $(M)$, stops for urban electric transport (ET), suburban $\left(S_{i}\right)$ and urban $\left(C_{I}\right)$ bus routes. The contour of relationships includes:

- order flow $\left(\lambda_{i j}\right)$;

- service flow $\left(\mu_{i j}\right)$ in the TTT resource channel;

- the parameters of the impact of the results of the TTT operation on the suburban $\left(\varphi_{\text {TTT-ua }}\right)$ and urban $\left(\varphi_{\text {TTT-иa }}\right)$ routes;

- parameters of the service time of the moments of service in TTT $\left(T_{s a}\right)$;

- the total time for servicing passengers in the TTT $\left(T_{p a s}\right)$, the parameters of the transport offer of the route $\left(A_{S A}\right)$.

The structure of the connection contour of the model of the suburban TTT is shown in Fig. 1.

In the presented structure of the model, based on the selected objective strategy, the criterion of the TTT effectiveness can be represented as the total time of transfer of passengers between routes: 


$$
T_{p a s}=\sum_{i=1}^{n} \sum_{j=1}^{k}\left(t_{d e p}^{j}-t_{a r r}^{i}\right) \cdot Q_{i} \cdot \beta_{i-j} \rightarrow \min ,
$$

where $t_{d e p}^{j}$ - the departure moment of vehicle of the $j$-th route from TTT; $t_{\text {arr }}^{i}$ - the arrival moment of vehicle of the $i$-th route in TTT; $Q_{i}$ - the volume of arrival of passengers from the $i$-th route, pass.; $\beta_{i-j}$ - the specific weight of transfers from the $i$-th route to the $j$-th route; $n$ - the number of suburban routes in the TTT; $k$ - the number of urban routes in the TTT.

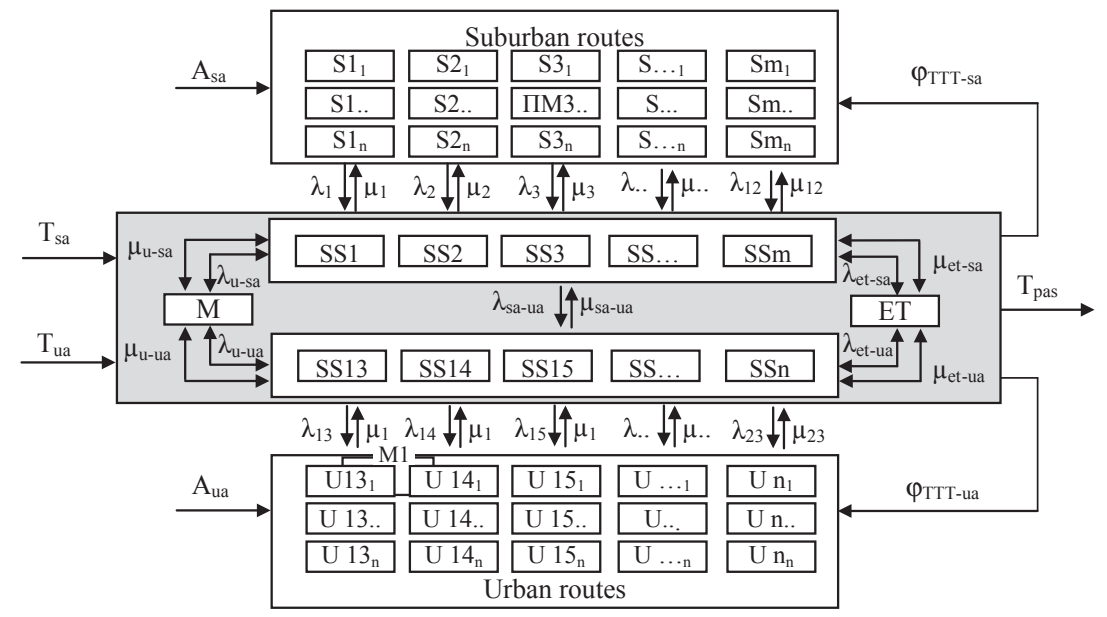

Fig. 1. Structure of the communication contour of the model of suburban transport and transfer terminals

The presented objective function should ensure achievement of its extreme value provided that the restrictions that are determined by the nature and conditions of the provision of a resource and social strategy for TTT functioning. These restrictions include the conditions for ensuring the appropriate level of capacity of the TTT stops to their available resource capabilities and the conditions for ensuring a balance of the number of vehicles on the routes and their environmental impacts to existing operating conditions of the routes. In view of these requirements, the system of limiting the objective function has the form:

$$
\left\{\begin{array}{l}
\mu_{i} \geq \mu_{i}^{p}, i=\overline{1, r}, \\
A_{m j} \leq A_{m j}^{p}, j=\overline{1, \omega}, \\
L_{p j} \leq L_{p j}^{p}, j=\overline{1, \omega},
\end{array}\right.
$$

where $\mu_{i}$ - service flow of the $i$-th stop station of the TTT, vehicle/hour; $\mu_{i}^{p}$ - the maximum allowable service flow of the $j$-th stop of the TTT, vehicle/hour; $A_{m j}-$ number of vehicles on the $j$-th route, units; $A_{m j}^{p}-$ maximum permissible number of vehicles on the $j$-th route, units; $L_{p j}$ - mileage of vehicles on the $j$-th route, $\mathrm{km} ; L_{p j}^{p}-$ maximum permissible mileage of vehicles on the $j$-th route, $\mathrm{km}$; $r$ - number of stops in the TTT; $j$ - number of routes in the TTL.

The service-resource model of TTT functioning provides, on the basis of the presented structure of elements and the contour of their interrelations, description of resource and service parameters. As the resource parameters in the model, indicators of the level of service flow of vehicles and passengers at the TTT stops, the parameters of the routes of suburban and urban communications, and the characteristics of the state of the stops are used. The service component of the model characterizes the indicators reflecting the quality of the transport services provided in the TTT, namely, the time spent by passengers for the implementation of transfers.

The order flow that arrives at the stopping point from the routes is determined on the basis of the arrival interval of the vehicles:

$$
\lambda_{i}=\frac{3600 \cdot T}{\sum_{u=1}^{k_{i}} \frac{I_{u}}{k_{u u}}},
$$

where $I_{u}$ - interval of vehicles arrival at the $i$-th stop of the $u$-th route, s; $k_{u u}-$ coefficient of unevenness of vehicles arrival at the $i$-th stop of the $u$-th route; $k_{i}-$ Number of routes in the $i$-th stop.

Flow of orders received for transfer in TTT from suburban routes:

$$
\lambda_{s a-u a}=\sum_{i=1}^{n} \lambda_{i} \cdot \sum_{j=1}^{k} \beta_{i-j} .
$$

The flow of orders received for transfer in TTT from the $i$-th suburban route to the $j$-th urban:

$$
\lambda_{\text {sai-uaj }}=\lambda_{i} \cdot \beta_{i-j} .
$$

Vehicle arrival interval:

$$
I_{m}=\frac{2\left(\sum_{a=1}^{l} t_{m_{a}}+\sum_{b=1}^{g} t_{i i_{b}}+t_{i s}+t_{T T T}\right)}{A_{m}},
$$

where $t_{\text {mov }_{a}}$ - movement time through route line, h.; $t_{i i_{b}}$ idle time at the intermediate stops, h.; $t_{i s}$ - idle time at the start stop, h.; $t_{T T T}$ - idle time in the TTT, h.; $l$ - the number of route lines; $g$ - the number of intermediate stops of the route.

The time of turnaround route:

$$
t_{t}=2\left(\sum_{a=1}^{l} t_{m o v_{a}}+\sum_{b=1}^{g} t_{i i_{b}}+t_{i s}+t_{T T T}\right) .
$$

The service flow at the stop is determined based on its capacity:

$\mu_{i}=P_{i}$.

Service flow in the suburban part of the TTT:

$$
\mu_{s a}=\sum_{i=1}^{r_{s a}} \mu_{i}=\sum_{i=1}^{r_{s a}} P_{i}
$$

where $r_{s a}$ - number of stops in the suburban part of the TTT.

Service flow in the urban part of the TTT:

$$
\mu_{u a}=\sum_{i=1}^{r_{u a}} \mu_{i}=\sum_{i=1}^{r_{u a}} P_{i}
$$

where $r_{u a}$ - number of stops in the urban part of the TTT. 
Total service flow in the TTT:

$$
\mu_{a}=\mu_{s a}+\mu_{u a}=\sum_{i=1}^{r} \mu_{i}=\sum_{i=1}^{r} P_{i}
$$

where $r$ - number of bus stops in the TTL.

Reducing the transfer time is possible by reducing the interval between the arrival of vehicles of joint routes. However, in the conditions of uncertainty of the time parameters of the route, such task becomes difficult and almost impossible in practical implementation. An alternative way to reduce the time of transfers is to introduce the principle of «cross-finding» vehicles in the TTT, where it is necessary to provide the maximum possibility of simultaneous idling of vehicles in the TTT during loadingunloading. The graphical representation of the formation of the transfer realization time is shown in Fig. 2.

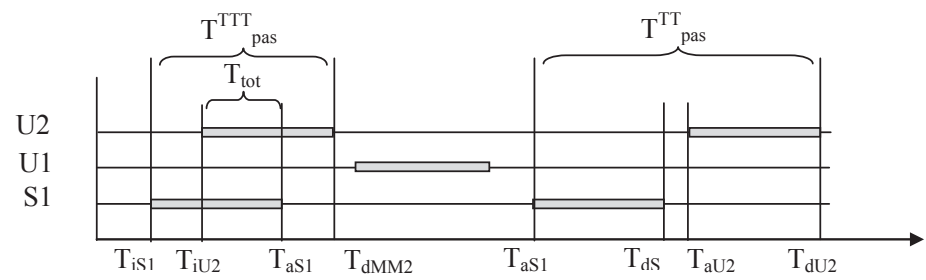

Fig. 2. Graphical representation of the transfer time

The transfer time of passengers between suburban and urban routes is determined on the basis of the difference in time between the arrival and departure of vehicles:

$$
t_{p a s_{i-j}}^{T T T}=\Delta t_{a S_{i}}+t_{a d_{i-j}}+\Delta t_{a U_{j}}
$$

where $\Delta t_{a s_{i}}$ - time between the arrival of the suburban route and the start of overlapped band, h.; $t_{a d_{i-j}}-$ overlapped band time, h.; $\Delta t_{a U_{j}}$ - time between departure of urban route and the end time of overlapped band, $h$.

The total time of transfer of passengers at TTT between suburban and urban routes:

$$
T_{\text {pas }}=\sum_{i=1}^{n} \sum_{j=1}^{k} t_{\text {pasi }}^{T T T} \cdot Q_{i} \cdot \beta_{i-j},
$$

де $Q_{i}$ - volume of arrival of passengers from the $i$-th route, pas.; $\beta_{i-j}-$ the proportion of transfers from the $i$-th route to the $j$-th route.

The operational state of the TTT stops can be determined by using the queuing system approaches. The TTT stops can be represented as a queuing system with one channel. Based on this presentation, it is possible to determine the parameters of its operation and assess the likelihood of a queue of vehicles at a stop.

The probability of the absence of a vehicle at a stop:

$$
P_{0 i}=\left(1+\rho_{i}+\rho_{i}^{2}+\rho_{i}^{3}+\ldots+\rho_{i}^{y}\right)^{-1},
$$

де $\rho_{i}$ - load level of the stop; $y$ - maximum number of queues.

The relationship between the order and service flows reflects the possible states of the system and determines the level of its load:

$$
\rho_{i}=\frac{\lambda_{i}}{\mu_{i}} .
$$

The probability of having a vehicle on arrival of the next vehicle at the stop:

$$
P_{1 i}=\rho_{i} P_{0 i}
$$

The probability of a queue of a vehicle when the next vehicle arrives at a stop:

$$
P_{2 i}=\rho_{i}^{2} P_{0 i}
$$

The conditions for the stable TTT functioning are the absence of queues and the possibility of its occurrence. Such condition can be written in the form of a restriction:

$$
P_{2 i}=0 \text {. }
$$

Accepted the probability of having vehicles in a stop as zero and substituted the values of the components of the order and service flow, it is possible to write the equation that defines the maximum permissible value of the flow of service:

$$
\begin{aligned}
& P_{2 i}=\left(\frac{3600}{P_{i} \cdot \sum_{u=1}^{k_{i}} \frac{I_{u}}{k_{\exists u}}}\right)^{2} \times \\
& \times\left(1+\frac{3600}{P_{i} \cdot \sum_{u=1}^{k_{i}} \frac{I_{u}}{k_{u u}}}+\left(\frac{3600}{P_{i} \cdot \sum_{u=1}^{k_{i}} \frac{I_{u}}{k_{u u}}}\right)^{2}\right)^{-1}=0 .
\end{aligned}
$$

The presented equation makes it possible to determine the absolute values of the parameters of the TTT functioning, under which conditions for the realization of certain resource and social substrategies of its functioning are ensured.

\section{Research results}

Based on the performed calculations, it is possible to analyze the change in the results of the TTT functioning depending on the time parameters of the interaction of the routes. Such analysis is carried out in analytical form and assumes its purpose to determine the main trends in the formation of internal cause-effect relationships. These links in the future will make it possible to become a tool for practical adaptation of the proposed technological solutions to the formation of a production program for the TTT functioning.

The analysis of the obtained data is carried out in three main directions:

- analysis of connection «the length of the overlapped band - the total transfer time of the passengers in the TTT between the considered routes - the value of the parameters of restriction system»;

- analysis of connection «duration of time between the arrival of the suburban route and the transfer time of the passengers in the TTT between the routes»; 
- analysis of connection «duration of time between the departure of the urban route and the transfer time of the passengers in the TTT between the routes - the value of the parameters of restriction system».

Investigation of the time parameters of interaction of passenger transport was carried out for the suburban TTT «Holodnaya Gora» in Kharkov (Ukraine). Determination of the range of permissible values for the parameters of interaction between vehicles in suburban TTT «Holodnaya Gora» is realized by identifying the area of permissible solutions, which is determined on the basis of an assessment of the compliance of the critical value of the restriction system. System of restrictions is: the right number of buses, the total mileage on the suburban route, the flow of maintenance of the resource channels of TTT. According to certain dependencies, it is established that the critical value of the duration of the overlapped band concerning the required number of buses is $4.5 \mathrm{~min}$., concerning to the bus run - $8.5 \mathrm{~min}$., concerning to the flow of service -5 min. Let's represent the area of permissible values of the parameters of the overlapped band duration on the graph, combining concerning to a certain restriction. This area of feasible solutions is shown in Fig. 3.

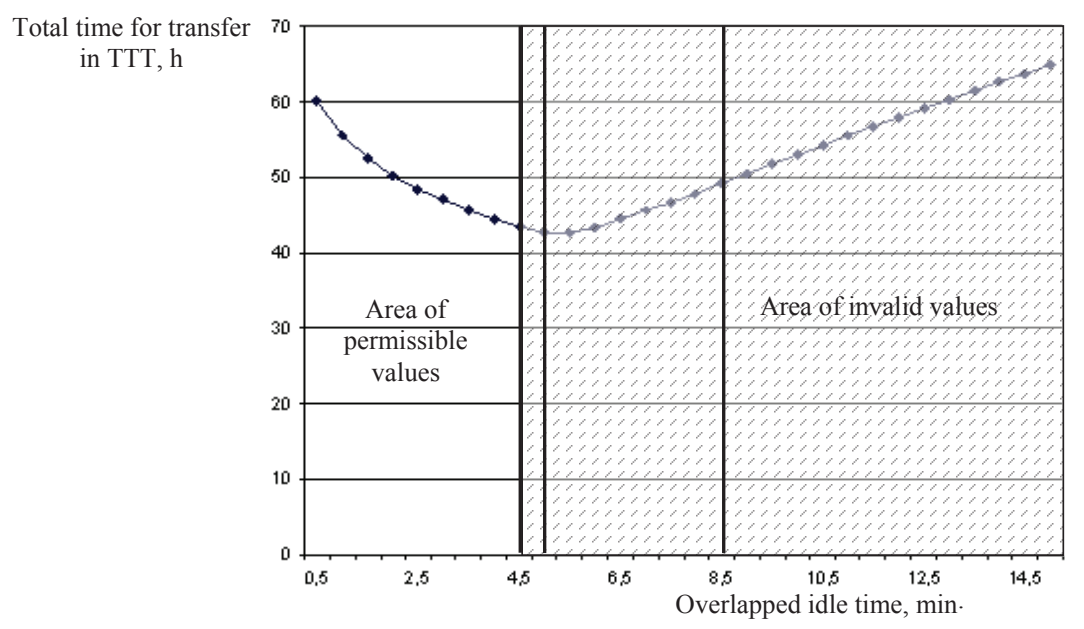

Fig. 3. The area of acceptable time values combining idle of the vehicles in transport and transfer terminals

The critical feature of the area of permissible values is the critical condition of their conformity with the value of the corresponding maintenance of the content in the existing boundaries of the resource balance (the number of buses on the route), the volume of harmful emissions. These emissions depend on the mileage on the route and the flow of service, determines the possible state of functioning of the TTT. The acceptable value of the band duration is 4.5 minutes, which provides a condition for matching existing resource capabilities and allows reducing the total time for passengers to change.

\section{SWOT analysis of research results}

Strengths. Isolation of the communication contour of the interaction model of elements within the suburban TTT made it possible to form a general view of the criterion for the efficiency of its functioning and to single out a system of restrictions that is based on the requirements for ensuring resource compliance with existing transport opportunities. The study of technological interaction from the point of view of the time of passenger transfer to TTT is the basis for the formation of the corresponding functional and production programs for the technological processes of passenger transport, aimed at improving the quality of transport services for the population. In combination with the methods of architectural and planning and technical development of TTT, this form allows to significantly increase the operational properties of its potential and provides the conditions for stabilizing its operation.

As strength of the research, it should be noted that the proposed form of coordination of interaction allows to ensure the balance of the resource capabilities of transport within their existing level. This principle is implemented on the basis of the principles of providing service-resource efficiency of technological processes and allows to use the proposed approach in the conditions of existing organizational and planning solutions of suburban TTT. Unlike the existing ones, this approach allows to increase the efficiency of transport services for passengers using technological solutions without attracting additional resources for the creation and reconstruction of transport infrastructure.

Weaknesses. The weak side of research is the need to create conditions for ensuring the accuracy of the timetable on routes passing through the TTT. Taking into account the complexity of the organization and the level of traffic loading of the transport networks of the route zone, the process of coordinating the interaction of passenger transport needs to be implemented within the framework of a comprehensive program for improving the work of transport. Such program should ensure the formation of conditions for limiting influential exchange with elements of the external environment and must be based on an assessment of the change in the system efficiency of passenger transport.

Opportunities. The proposed model for determining the time parameters of interaction in suburban TTTs is an integral structural element of an integrated information management system for passenger transport. The characteristic conditions for determining the rational time for the adjacent location of vehicles have been created, which make it possible to shorten the procedure for determining efficient technological schemes for the operation of passenger transport and ensure the possibility of their adaptation to the specific production conditions of the corresponding TTTs.

Threats. The difficulty in determining the rational time parameters of interaction in suburban TTT is the need to obtain operational objective information about the conditions of traffic of vehicles, the level of transport demand and the state of their fluctuations in time. These factors have a significant impact on the service-resource indicators of interaction and must be taken into account in the operational mode. To do this, it is necessary to create a system for collecting information and introducing a single coordinating center for its processing. 


\section{Conclusions}

1. The general structure of interaction in suburban TTT of subjects of the transport process, based on an estimation of time of change of passengers is generated. Effective technological coordination of interaction is achieved by taking into account the parameters of order and service flows, taking into account the reverse effect of the performance results on the service-resource characteristics of the work of routes passing through the TTT. The use of this form of interaction representation of passenger transport makes it possible to implement the procedure for finding rational time parameters for the simultaneous finding of vehicles of various types of services in suburban TTT that minimize the time spent on transfer of the passengers in accordance with the existing capabilities of resource service channels.

2. To make a decision on determining the length of the idle time of vehicles during the technological operations of loading and unloading of the passengers it is suggested to use the developed mathematical model for determining the boundaries of the permissible parametric areas of time interaction of passenger transport in suburban TTT. The developed model takes into account the probability of the status of the resource service channel and the change in the volume of route resources. On the basis of the conducted researches, characteristic conditions and areas of acceptable values of the rational duration of the overlapped location of vehicles in suburban TTT are established, which are an integral part of the overall technological process of the work of passenger transport on the routes of suburban traffic.

\section{References}

1. Bondar, A. Transport interchange hub as part of city planning structure [Text] / A. Bondar // Mining, construction, road and melioration machines. - 2016. - № 88. - P. 91-99.

2. Krystopchuk, M. Ye. Do pytannia rozmishchennia miskykh transportno-peresadochnykh vuzliv [Text] / M. Ye. Krystopchuk, Z. V. Bychko // Komunalne hospodarstvo mist. - 2012. № 103. - P. 374-378.

3. Morozova, Y. B. Principles and methods of architectural planning of passenger terminals in the republic of Belarus [Text] / Y. B. Morozova, D. V. Zharkevich // Architecture. - 2013. Vol. 6 (40). - P. 208-212.

4. Azarenkova, Z. V. Planning Organization of Transport Transferring Junction [Text] / Z. V. Azarenkova // Academia. Arhitektura i stroitel'stvo. - 2011. - № 1. - P. 76-80.

5. Mikhailov, A. Iu. Classifying characteristics of intermodal connections of city public transport at the example of Vienna [Text] / A. Iu. Mikhailov, T. A. Kopylova // Izvestiya vuzov. Investitsiyi. Stroyitelstvo. Nedvizhimost. - 2015. - № 1 (12). P. 137-144.

6. Reitsen, E. A. Organizatsiia peresadok s linii GPT na metropoliten i logistika [Text] / E. A. Reitsen, A. I. Berlog // Vestnik Donetskoi akademii avtomobil'nogo transporta. - 2012. № 3. - P. 4-11.
7. Dessouky, M. Real-time control of buses for schedule coordination at a terminal [Text] / M. Dessouky, R. Hall, L. Zhang, A. Singh // Transportation Research Part A: Policy and Practice. - 2003. - Vol. 37, № 2. - P. 145-164. doi:10.1016/ s0965-8564(02)00010-1

8. Sorensen, C. H. Increased coordination in public transport which mechanisms are available? [Text] / C. H. Sorensen, F. Longva // Transport Policy. - 2011. - Vol. 18, № 1. P. 117-125. doi:10.1016/j.tranpol.2010.07.001

9. Vdovychenko, V. O. Development of a mathematical model of public transport interchanges functioning [Text] / V. O. Vdovychenko, G. O. Samchuk // Bulletin of NTU «KhPI». Series: Mechanical-technological systems and complexes. - 2016. № 17 (1189). - P. 56-61.

10. $\mathrm{Wu}, \mathrm{W}$. Designing robust schedule coordination scheme for transit networks with safety control margins [Text] / W. Wu, R. Liu, W. Jin // Transportation Research Part B: Methodological. - 2016. - Vol. 93. - P. 495-519. doi:10.1016/ j.trb.2016.07.009

11. Nesheli, M. M. Improved reliability of public transportation using real-time transfer synchronization [Text] / M. M. Nesheli, A. A. Ceder // Transportation Research. Part C: Emerging Technologies. - 2015. - Vol. 60. - P. 525-539. doi:10.1016 j.trc.2015.10.006

12. Ibarra-Rojas, O. J. Multiperiod Bus Timetabling [Text] O. J. Ibarra-Rojas, F. Lopez-Irarragorri, Y. A. Rios-Solis // Transportation Science. - 2016. - Vol. 50, № 3. - P. 805-822. doi:10.1287/trsc.2014.0578

13. Li, L. Urban Transit Coordination Using an Artificial Transportation System [Text] / L. Li, H. Zhang, X. Wang, W. Lu, Z. $\mathrm{Mu} / /$ IEEE Transactions on Intelligent Transportation Systems. - 2011. - Vol. 12, № 2. - P. 374-383. doi:10.1109/ tits.2010.2060195

14. Wu, Y. Multi-objective re-synchronizing of bus timetable: Model, complexity and solution [Text] / Y. Wu, H. Yang, J. Tang / Transportation Research Part C: Emerging Technologies. 2016. - Vol. 67. - P. 149-168. doi:10.1016/j.trc.2016.02.007

\section{РАЗРАБОТКА МОДЕЛИ ОЛРЕДЕЛЕНИЯ ВРЕМЕННЫХ ПАРАМЕТРОВ ВЗАИМОДЕЙСТВИЯ ПАССАЖИРСКОГО ТРАНСПОРТА В ПРИГОРОДНОМ ТРАНСПОРТНО-ЛЕРЕСАДОЧНОМ} TEPМИНАЛЕ

Сформирована общая структура и представлены составляющие элементы модели технологического взаимодействия пассажирского транспорта в пригородном транспортно-пересадочном терминале. На основе оценки общего времени пересадки пассажиров выделены характеристические условия и области допустимых значений рациональной продолжительности времени смежного нахождения транспортных средств в пригородном транспортно-пересадочном терминале.

Ключевые слова: пригородный транспортно-пересадочный терминал, пассажирский транспорт, время пересадки пассажиров, время смежного простоя.

Vdovychenko Volodymyr, PhD, Associate Professor, Department of Transport Technology, Kharkiv National Automobile and Highway University, Ukraine, e-mail: Vval2301@gmail.com, ORCID: http:// orcid.org/0000-0003-2746-8175 